\title{
PENGELOLAAN LAHAN PEKARANGAN/KEBUN DENGAN SENGON SOLOMON HASIL KULTUR IN VITRO PADA KELOMPOK USAHA PEMBIBITAN SENGON DI KABUPATEN MALANG
}

\author{
Wiwik Kusmawati ${ }^{1}$, Moh. Zaini $^{2}$, Yusvidha Ernata ${ }^{3}$ \\ ${ }^{1,2,3)}$ IKIP Budi Utomo, Malang, Jawa Timur, Indonesia \\ 1*Email: wiwikkusmawati@gmail.com \\ ${ }^{2}$ Email: pojur zen@yahoo.com \\ ${ }^{3}$ Email: yusvidaernata@gmail.com
}

\begin{abstract}
Sengon nursery business groups, especially in Poncokusumo Subdistrict and Wajak Subdistrict, Malang Regency still rely on sengon seeds that grow wild in nature with low growth rates. Though sengon seeds are a commodity of high economic value. This can be seen from the small number of breeders who manage the sengon seeds well. Even though the availability of plant seeds is a factor that plays a major role in the success of the sengon plant forest development program. Quality seeds with the support of aquaculture technology can provide high quality seeds so they can produce quality trees and wood products. The stages of implementing PKM activities are as follows: (a) Survey and planning, (b) Counseling and training "Optimization of Yard / Garden Land Management with Sengon Solomon Results of In Vitro Culture in Sengon Nursery Groups in Malang Regency", and (c) Cultivation Solomon's sengon seeds from in vitro culture. The results achieved through this community service program are resolving some of the partners 'problems, namely sengon breeders still rely on sengon seeds that grow wild in nature, lack of sengon seedlings, lack of public understanding of solomon sengon cultivation technology, limited breeders' ability to seed sengon, and low superior sengon seeds produced, which have an impact on the amount of sengon seedlings produced. The activities carried out have succeeded in supporting the service program, namely counseling and training on "Optimizing the Management of Yard / Garden Land with Sengon Solomon Results of In Vitro Culture in Sengon Nursing Business Groups in Malang Regency", and cultivating the seeds of sengon solomon from in vitro culture.
\end{abstract}

Keyword: land yard/garden, sengon solomon, culture in vitro, Malang regency

\section{PENDAHULUAN}

RKPD Kabupaten Malang Tahun 2015 (2015) mengatakan wilayah Kabupaten Malang terletak antara $112^{\mathrm{O}} 17^{\prime} 10,90^{\prime \prime}$ $112^{\mathrm{O}} 57^{\prime} 00,00$ " Bujur Timur, $7^{\mathrm{O}} 44^{\prime} 55,11^{\prime \prime}$ $8^{\mathrm{O}} 26$ '35,45" Lintang Selatan. Dengan batas wilayah administrasi terdiri dari: sebelah utara: Kabupaten Pasuruan, Kabupaten Probolinggo, Kabupaten Mojokerto dan Kabupaten Jombang; sebelah timur: Kabupaten Lumajang; sebelah selatan: samudera Indonesia; sebelah barat: Kabupaten Blitar dan Kabupaten Kediri. Sedangkan di bagian tengah wilayah
Kabupaten Malang berbatasan dengan kota Malang dan kota Batu. Luas wilayah 353.486 ha. Secara administratif, wilayah Kabupaten Malang terdiri dari 33 Kecamatan, 12 kelurahan, 378 desa, 3.147 Rukun Warga (RW) dan 14.700 Rukun Tetangga (RT).

Topografi Kabupaten Malang terdiri dari dataran rendah, dataran tinggi, gununggunung yang aktif maupun tidak aktif serta sungai-sungai yang melintasi wilayah KabupatenMalang, dimana faktor sumber daya alam tersebut mencakup aspek kondisi topografi yang besar pengaruhnya terhadap proses pembangunan. Wilayah Kabupaten Malang di bagian barat, bagian timur dan 
utara dikelilingi oleh pegunungan, sehingga daerahnya cenderung terjal atau bergelombang (berbukit) dengan kelerengan diatas $40 \%$, meliputi wilayah Kecamatan Pujon, Kecamatan Ngantang, Kecamatan Kasembon, Kecamatan Poncokusumo, Kecamatan Wajak, Kecamatan Jabung, Kecamatan Ampelgading dan Kecamatan Tirtoyudo. Dengan adanya kondisi topografi tersebut, maka wilayah Kabupaten Malang mempunyai potensi sebagai kawasan lindung khususnya bagi kawasan yang ada dibawahnya. Sehingga berdampak positif karena kelestarian tanah dan air dapat terjaga dengan baik. Selain itu wilayah Kabupaten Malang mempunyai potensi pengembangan di bidang pertanian dan pariwisata. Untuk pengembangan di bidang pertanian lebih diutamakan pertanian hortikultura dan perkebunan, karena umumnya daerah-daerah dengan kelerengan tersebut mempunyai iklim (suhu) yang lebih sejuk dan sangat cocok untuk jenis tanaman perkebunan yaitu sengon(Paraserianthes falcataria (L.) Nielsen). Berdasarkan pengamatan awal di lokasi pengabdian, Kabupaten Malang memiliki kondisi lingkungan alam yang subur dengan ketinggian wilayah antara 500 - 3600 dpl. Kondisi lingkungan tersebut sangat sesuai untuk sengon sehingga sengon dapat tumbuh dengan baik.

Penggunaan lahan di Kabupaten Malang meliputi: permukiman/kawasan terbangun $22,76 \%$; industri $0,17 \%$; sawah $13,04 \%$; pertanian lahan kering $23,65 \%$; perkebunan $6,10 \%$; hutan $28,59 \%$; rawa/waduk $0,20 \%$; tambak/kolam $0,03 \%$; padang rumput/tanah kosong $0,29 \%$; tanah tandus/tanah rusak 1,54\%; tambang galian $0,26 \%$; lain-lain 3,26\%.

Sengon merupakan salah satu alternatif dan menjadi primadona baru dalam bidang perkayuan karenacepat tumbuh (fast growing species), dapat ditanam di berbagai kondisi tanah, kayunya cenderung lebih lurus, masa tebang lebih pendek, sifat kayunya termasuk kelas awet dan kuat IV/V serta berat jenis 0,24-0,49 dengan rata-rata 0,33. Prospek penggunaan untuk pulp/kertas termasuk kategori sedang. Martawijaya dan
Kartasujana (1977) mengatakan kayu sengon dapat dimanfaatkan sebagai serat dan bahan papan, peti kemas, kotak kemasan, kayu pertukangan, perabot rumah tangga, korek api, sumpit, dan lain-lain. Anonimous (1987) mengatakan bahwa secara ekologis pohon sengon dapat meningkatkan kualitas lingkungan seperti: meningkatkan kesuburan tanah, memperbaiki tata air, dan menciptakan iklim mikro. Hal ini disebabkan sifat morfologis dari famili legum yaitu memiliki perakaran yang sangat dalam dan serasah daun cepat melapuk. Berdasarkan kriteria tersebut, maka sengon banyak dikembangkan sebagai komoditas dalam pengusahaan hutan tanaman, baik dalam skala besar seperti Hutan Tanaman Industri (HTI), reboisasi, dan penghijauan maupun skala kecil yaitu banyak ditanam dikebun-kebun rakyat dengan sistem tumpang sari.

Kelompok usaha pembibitan sengon di Kecamatan Poncokusumo dan Kecamatan Wajak Kabupaten Malang membibit sengon dengan biji. Biji tersebut dapat dibeli di penangkar benih, kios-kios pertanian, ataupun dicari dibawah pohon induk. Jumlah biji sengon sebanyak 42000 per kg dengan perkecambahan biji muda dan hanya membutuhkan perendaman air semalam. Agar perkecambahan seragam, biji-biji tersebut dapat dimasukan dalam air panas atau dalam air selama 15 menit. Anakan sengon ditanam setelah tiga bulan di persemaian dan akan tumbuh cepat di lahan (NAS, 1983 dalam NFTA World Education, 1991).

Faktor yang sangat berperan dalam menyukseskan program pembangunan hutan tanaman sengon adalah ketersediaan bibit tanaman. Bibit yang berkualitas baik dapat diperoleh dengan teknologi budidaya. Penanganan benih dan bibit dengan tepat selama di persemaian merupakan bagian dari teknik pembibitan, dengan harapan memperoleh pertumbuhan sengon secara optimal. Pembibitan secara konvensional kadangkala masih menggunakan pupuk kimia untuk meningkatkan kesuburan tanah daripada media. Kelemahan dari pupuk kimia adalah menimbulkan pencemaran 
lingkungan, penggunaan yang berlebihan dapat merusak tanaman dan sifat fisik tanah, serta harganya mahal. Sangatlah penting untuk mengoptimalkan penggunaan lahan pekarangan/kebun dengan bibit sengon solomonhasil kultur in vitropada kelompok usaha pembibitan sengon di Kecamatan Poncokusumo dan Kecamatan Wajak Kabupaten Malang.

Trubusid (2008) mengatakan sengon solomon memiliki pertumbuhan yang relatif homogen dan produktivitasnya tinggi. Sengon solomon merupakan varietas sengon terbaru yang teridentifikasi dan terbukti tumbuh jauh lebih cepat dibandingkan dengan provenance sengon yang lain yang sebelumnya telah dikenal di Indonesia. Sengon solomon berasal dari Kepulauan Solomon, Samudera Pasifik, yang bertanah vulkanik nan subur. Hasil penelitian dan percobaan penanaman di beberapa lokasi membuktikan keunggulan sengon solomon dibandingkan dengan sengon lokal. Keunggulan sengon salomon dibandingkan sengon lokal ini dapat dilihat pada Tabel 1 berikut ini.

Berdasarkan hasil observasi, pertumbuhan sengon solomon pada umur lima tahun memiliki diameter (DBH) ratarata $31 \mathrm{~cm}$ dan tinggi 22 meter. Selain tinggi dan diameter batang, keunggulan sengon solomon dapat dilihat dari tingkat vigor, viabilitas, kelurusan batang, dan percabangan. Warna batang putih abu-abu cerah mengidentifikasikan tanaman memiliki vigor dan viabilitas yang baik. Sengon solomon tumbuh lebih lurus dan silindris dengan percabangan yang ringan (tidak terlalu rindang). Dari data di atas, dapat diasumsikan kayu yang akan diperoleh dengan luasan tertentu yang dapat dilihat pada Tabel 2 sebagai berikut:

Tabel 1. Perbandingan Tinggi dan Diameter Sengon Solomon dan Sengon Lokal

\begin{tabular}{lcccc}
\hline Varietas & \multicolumn{3}{c}{ Tinggi $(\mathbf{m})$} & \multicolumn{2}{c}{ Diameter $(\mathbf{c m})$} \\
\cline { 2 - 6 } & $\mathbf{2}$ th & $\mathbf{3}$ th & $\mathbf{2}$ th & $\mathbf{3}$ th \\
Solomon & 8 & 10 & 16 & 19 \\
Lokal & 7 & 8 & 12 & 16 \\
\hline
\end{tabular}

Tabel 2. Potensi Kayu Sengon Solomon

\begin{tabular}{cc}
\hline Luas penanaman & $\mathbf{1 . 0 0 0}$ hektare \\
\hline Jarak tanam awal & $3 \times 3$ meter \\
Kerapatan tanam awal & 1.110 pohon/hektare \\
Kerapatan akhir & 500 pohon/hektare \\
Masa tanam & 5 tahun \\
Rata-rata tinggi & 22 meter \\
Rata-rata DBH & $31 \mathrm{~cm}$ \\
Volume/pohon & $0,85 \mathrm{~m}^{3} /$ pohon \\
Volume/hektare & $425 \mathrm{~m}^{3}$ \\
Volume/1.000 hektare & $425.000 \mathrm{~m}^{3}$ \\
\hline
\end{tabular}

Keterangan: Rumus volume/pohon : 0,00004 (DBH) ${ }^{2}$ x tinggi

Laboratorium Silvikultur (2007) mengatakan buah sengon solomon berbentuk polong, pipih, tipis, tidak bersekat-sekat dan panjangnya sekitar $6-12 \mathrm{~cm}$. Setiap polong buah berisi 15 - 30 biji. Jumlah biji dalam setiap buahnya lebih sedikit dari sengon laut dan sengon morotai. Polong yang telah masak berwarna hijau gelap atau coklat. Ketika polong kering biji akan keluar dari polong. Sanusi (2008) mengatakan bentuk biji mirip perisai kecil, pipih, lonjong, $3-4 \mathrm{x}$ $6-7 \mathrm{~mm}$, waktu muda berwarna hijau, bagian tengah coklat dan jika sudah tua biji akan berubah kuning sampai berwarna coklat kehitaman, agak keras dan berlilin. Harga sekilo benih Rp 2,5-juta terdiri atas 20.00025.000 biji (Trubusid, 2008). Kayu sengon solomon lebih lunak, hampir seperti sengon merah. Sengon solomon, pada umur kira - 
kira 5 - 6 tahun biasanya mudah patah terkena angin kencang (Lee, 2009).

Tingkat pembungaan dan pembuahan sengon solomon masih tergolong rendah. Sementara itu, pengambilan benih langsung ke tempat asalnya dianggap tidaklah efisien dan harus melalui prosedur legalitas yang relatif sulit. Karena itu, perbanyakan sengon solomon biasanya dilakukan dengan kultur in vitro atau dikenal juga dengan istilah kultur jaringan. Selain cepat, jumlah bibit yang dihasilkan relatif banyak. Melalui kultur in vitro, bibit yang diperoleh memiliki susunan genetik yang identik dengan indukannya dan memiliki potensi pertumbuhan yang sama pula. Keuntungan lain kultur in vitro yaitu bibit yang dihasilkan biasanya bebas hama dan penyakit sehingga kekhawatiran petani dan praktisi penanaman sengon terhadap penyakit kanker karat kayu (Uromycladium tepprianum) dapat terminimalisir.

Gunawan (1992) mengatakan kultur in vitro merupakan suatu metode untuk mengisolasi bagian dari tanaman seperti protoplasma, sel, sekelompok sel, jaringan dan organ serta menumbuhkannya dalam kondisi aseptik, sehingga bagian-bagian tersebut dapat memperbanyak diri dan beregenerasi menjadi tanaman utuh kembali. Penggunaan metode ini tidak saja memungkinkan diperolehnya tanaman yang seragam dan memiliki sifat yang sama dengan induknya, tetapi juga dapat diperbanyak dalam jumlah yang besar dan tersedia dalam waktu yang cepat. Bonga dan Durzan (1982) mengatakan dalam bidang kehutanan, penggunaan teknik kultur in vitro secara komersial masih dalam tahap pengembangan dan perkembangannya cukup menjanjikan untuk masa yang akan datang. Potensi penggunaan kultur in vitro pada industri bidang kehutanan sangat besar.

Kelompok usaha pembibitan sengon di Kecamatan Poncokusumo dan Kecamatan Wajak Kabupaten Malang membibit sengon dengan biji. Pembibit sengon di Kabupaten Malang masih mengandalkan bibit sengon yang tumbuh liar di alam dengan tingkat keberhasilan tumbuhnya yang sangat rendah. Kelompok usaha pembibitan sengon di
Kabupaten Malang sebagai produsen bibit sengon belum menganggap bibit sengon sebagai suatu komoditi yang sangat bernilai ekonomi tinggi. Terlihat dari sedikitnya jumlah pembibit yang mengelola bibit sengon dengan baik. Ketersediaan bibit tanaman merupakan faktor yang berperan dalam menyukseskan program pembangunan hutan tanaman sengon. Bibit yang sangat berkualitas dengan dukungan teknologi budidaya dapat menyediakan benih-benih yang memiliki kualitas yang sangat tinggi sehingga dapat menghasilkan pohon dan hasil kayu yang sangat bermutu.

Terbatasnya kemampuan pembibit sengon di Kabupaten Malang dalam membibit sengon menjadi salah satu penyebab mereka kurang memiliki daya saing dalam menawarkan bibit sengon, sehingga keuntungan dari hasil penjualan yang didapatnya sangatlah sedikit. Harga bibit sengon yang dijual lebih ditentukan oleh para pembeli sehingga memposisikan pembibit sengon sebagai penerima harga (price taker). Posisi tersebut mengakibatkan peran pembeli sangatlah lebih menonjol dan mendapatkan keuntungan yang lebih besar dibandingkan pembibit sengon itu sendiri.

Apalagi kelompok usaha pembibitan sengon dengan skala kecil atau skala rumahan sangat kalah dalam menghasilkan bibit sengon yang unggul dibandingkan dengan kelompok usaha skala besar. Akibat rendahnya bibit sengon unggul yang dihasilkan oleh kelompok usaha pembibitan sengon, maka akan berdampak pada jumlah produksi bibit sengon yang dihasilkan. Sehingga berpengaruh terhadap finansial bagi masyarakat kelompok usaha pembibitan sengon di Kabupaten Malang, sehingga omzet bulanan para kelompok usaha pembibitan sengon menurun dan itu merupakan pemicu kerugian awal. Sehingga perlu dicarikan solusi untuk mengatasi hal tersebut dalam bentuk mencoba varian lain dari jenis sengon solomon (P. Falcataria $v$. solomonensis).

Oleh karena itu penggunaan lahan pekarangan/kebun dengan bibit sengon solomon hasil kultur in vitro harus 
dioptimalkan pada kelompok usaha pembibitan sengon di Kabupaten Malang. Sengon solomon memiliki pertumbuhan yang relatif homogen dan produktivitasnya tinggi. Berdasarkan hasil pengamatan, pertumbuhan sengon solomon pada umur lima tahun memiliki diameter $(\mathrm{DBH})$ rata-rata $31 \mathrm{~cm}$ dan tinggi 22 meter. Selain tinggi dan diameter batang, keunggulan sengon solomon dapat dilihat dari tingkat vigor, viabilitas, kelurusan batang, dan percabangan. Warna batang putih abu-abu cerah mengidentifikasikan tanaman memiliki vigor dan viabilitas yang baik. Sengon solomon tumbuh lebih lurus dan silindris dengan percabangan yang ringan (tidak terlalu rindang).

\section{METODE PELAKSANAAN}

Untuk mengoptimalkan kegiatan pengelolaan lahan pekarangan/kebun dengan sengon solomon hasil kultur in vitro pada kelompok usaha pembibitan sengon di kabupaten Malang maka perlu disusun tahapan pelaksanaan agar kegiatan PKM ini dapat berjalan dengan baik. Tahapan pelaksanaan kegiatan PKM adalah sebagai berikut:

1. Survei dan perencanaan

Kegiatan survei ini dilakukan dengan cara berkoordinasi dan melihat lokasi kegiatan pengabdian PKM bersamasama dengan mitra. Adapun tempat mitra adalah kecamatan Poncokusumo dan kecamatan Wajak kabupaten Malang.

2. Penyuluhan dan pelatihan "Pengelolaan Lahan Pekarangan/Kebun dengan Sengon Solomon Hasil Kultur in Vitro pada Kelompok Usaha Pembibitan Sengon Di Kabupaten Malang" di tempat mitra.

3. Budidaya bibit sengon solomon hasil kultur in vitro.

\section{HASIL DAN PEMBAHASAN}

\section{A. Hasil Pengabdian Kepada Masyarakat}

Hasil yang telah dicapai dalam program pengabdian kepada masyarakat
"Optimalisasi Pengelolaan Lahan Pekarangan/Kebun dengan Sengon Solomon Hasil Kultur in Vitro pada Kelompok Usaha Pembibitan Sengon Di Kabupaten Malang" adalah sebagai berikut:

\section{Survei dan Perencanaan}

Kegiatan survei ini dilakukan dengan cara berkoordinasi dan melihat lokasi kegiatan pengabdian PKM bersama dengan mitra. Tempat mitra adalah kecamatan Poncokusumo dan kecamatan Wajak kabupaten Malang. Sedangkan perencanaan dalam program pengabdian kepada masyarakat meliputi penyuluhan dan pelatihan "Pengelolaan Lahan Pekarangan/Kebun dengan Sengon Solomon Hasil Kultur in Vitro pada Kelompok Usaha Pembibitan Sengon Di Kabupaten Malang" dan budidaya bibit sengon solomon hasil kultur in vitro. Pada diskusirencana kegiatan ini melibatkan kedua mitra baik pak Soleh maupun pak Saipul sebagai mitra. Pada perencanaan dalam program pengabdian kepada masyarakat ini bertujuan untuk bertukar pikiran, sharing dan mendapatkan saran dan masukan, umpan balik serta terjalin komunikasi yangbaik dengan kedua mitra. Pada kegiatan ini juga dirancang dan membahas tentang kegiatan yang akan dilakukan pada \pm 8 bulan ke depan yang telah disepakati oleh kedua mitra.

2. Kegiatan Penyuluhan dan Pelatihan "Pengelolaan Lahan Pekarangan/ Kebun dengan Sengon Solomon Hasil Kultur in Vitro pada Kelompok Usaha Pembibitan Sengon Di Kabupaten Malang"

Dokumentasi penyuluhan dan pelatihan "Pengelolaan Lahan Pekarangan/Kebun dengan Sengon Solomon Hasil Kultur in Vitro pada Kelompok Usaha Pembibitan Sengon Di Kabupaten Malang" ini dapat dilihat pada Gambar 1.

\section{Budidaya Bibit Sengon Solomon Hasil Kultur In Vitro}

Dokumentasi kegiatan budidaya bibit sengon solomon hasil kultur in vitro tampak pada Gambar 2. 


\section{B. Pembahasan}

Pada kegiatan pengabdian ini ada beberapa hal yang dikaji meliputi :

1. Sengon Lokal vs Sengon Solomon

Sengon Solomon merupakan varietas sengon terbaru yang teridentifikasi dan terbukti tumbuh jauh lebih cepat dibandingkan dengan provenance sengon lain yang sebelumnya telah dikenal di Indonesia. Hasil penelitian dan percobaan penanaman di beberapa lokasi membuktikan keunggulan sengon solomon dibandingkan dengan sengon lokal. Perbedaan kedua jenis sengon dapat dilihat pada Gambar 3.

2. Kajian Tentang Sengon Solomon

Pohon Sengon Solomon berukuran sedang sampai besar, tinggi dapat mencapai $40 \mathrm{~m}$, tinggi batang bebas cabang $20 \mathrm{~m}$. Tidak berbanir, kulit licin, berwarna kelabu muda, bulat agak lurus. Diameter pohon dewasa bisa mencapai $100 \mathrm{~cm}$ atau lebih. Tajuk berbentuk perisai, jarang, selalu hijau. Daun Sengon tersusun majemuk menyirip ganda panjang dapat mencapai $40 \mathrm{~cm}$, terdiri dari 8 - 15 pasang anak tangkai daun yang berisi 15 - 25 helai daun, dengan anak daunnya kecilkecil dan mudah rontok. Warna daun hijau pupus, berfungsi untuk memasak makanan dan sekaligus sebagai penyerap nitrogen dan karbon dioksida dari udara bebas.

3. Keunggulan Sengon Solomon Hasil Kultur in Vitro

Tingkat pembungaan dan pembuahan sengon solomon masih rendah. Sementara itu, pengambilan benih langsung ke tempat asalnya dianggap tidak efisien dan harus melalui prosedur legalitas yang relatif sulit. Karena itu, perbanyakan tanaman sengon Solomon dilakukan dengan kultur jaringan. Selain cepat, jumlah bibit yang dihasilkan relatif banyak. Melalui kultur jaringan, bibit yang diperoleh memiliki susunan genetik yang identik dengan indukannya dan memiliki potensi pertumbuhan yang sama pula.
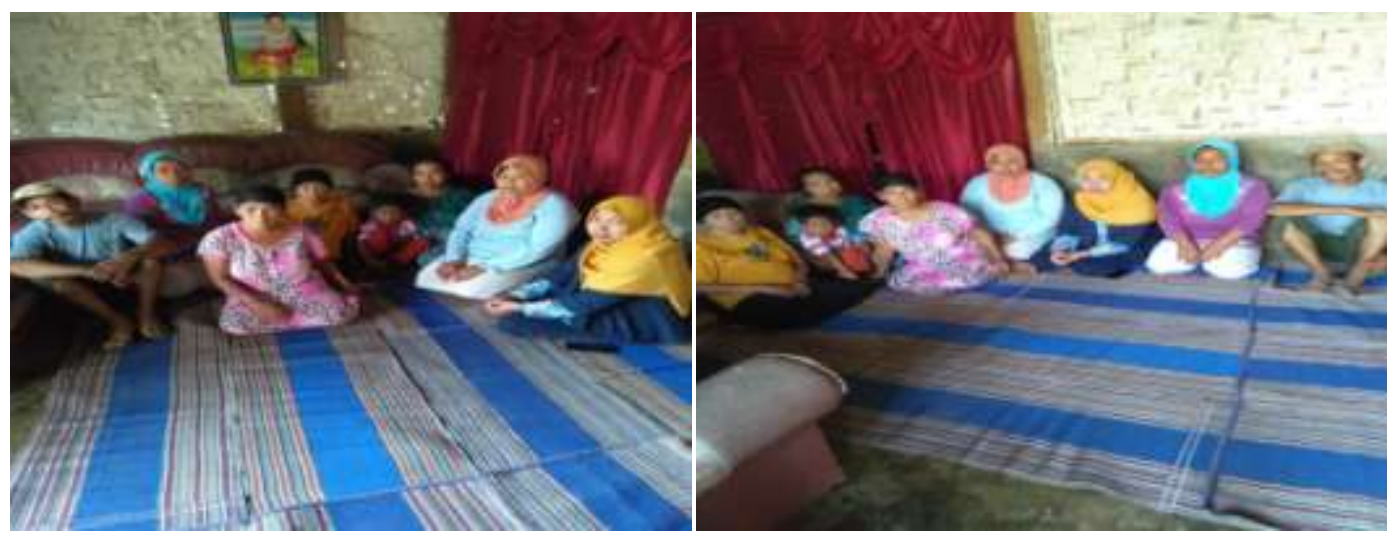

Gambar 1. Penyuluhan dan Pelatihan Pengelolaan Lahan Pekarangan/Kebun dengan Sengon Solomon Hasil Kultur in Vitro (Sumber: doc. Pribadi, 2018)

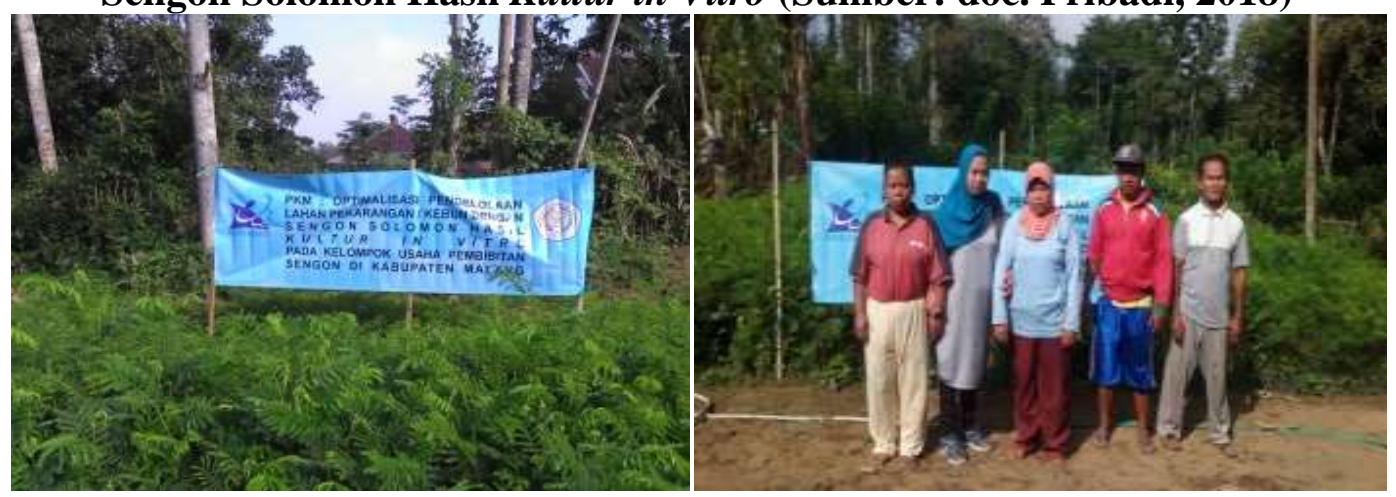

Gambar 2. Budidaya Bibit Sengon Solomon Hasil Kultur in Vitro (Sumber: doc. Pribadi, 2018) 


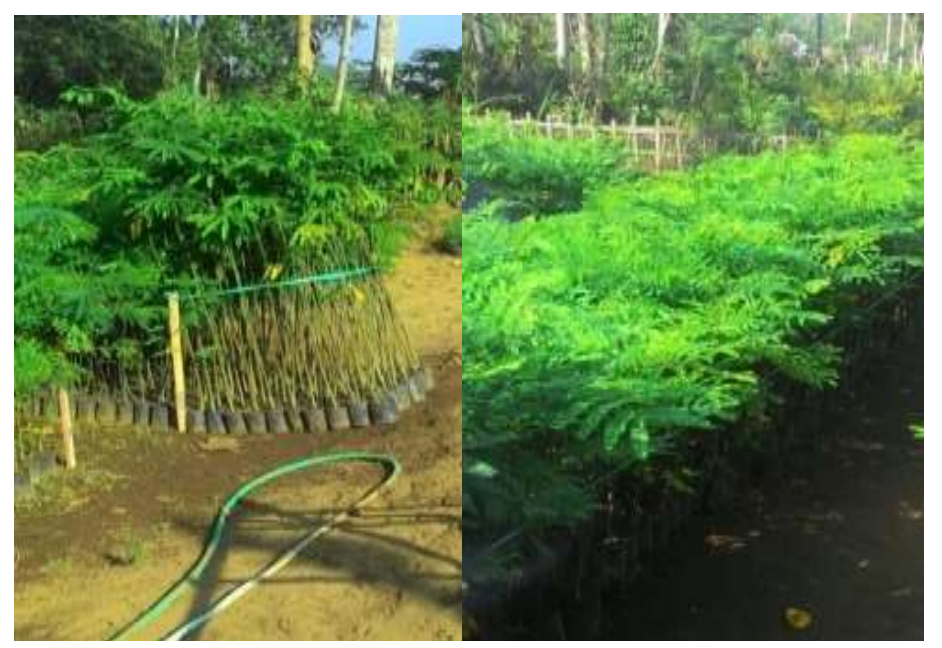

\section{Gambar 3. Sengon Lokal (A/kiri) dan Sengon Solomon Hasil Kultur in Vitro (B/kanan) (Sumber: doc. Pribadi, 2018)}

4. Sengon Solomon Hasil Kultur in VitroTingkatkan Usaha Pembibitan Sengon

Berdasarkan hasil pengamatan, pertumbuhan sengon solomon pada umur lima tahun memiliki diameter $(\mathrm{DBH})$ ratarata $31 \mathrm{~cm}$ dan tinggi 22 meter. Selain tinggi dan diameter batang, keunggulan sengon solomon dapat dilihat dari tingkat vigor, viabilitas, kelurusan batang, dan percabangan. Warna batang putih abu-abu cerah mengidentifikasikan tanaman memiliki vigor dan viabilitas yang baik. Sengon solomon tumbuh lebih lurus dan silindris dengan percabangan yang ringan (tidak terlalu rindang).

5. Hama dan Penyakit pada Sengon Solomon Hasil Kultur in Vitro

Keuntungan lain kultur in vitro yaitu bibit yang dihasilkan biasanya bebas hama dan penyakit sehingga kekhawatiran petani dan praktisi penanaman sengon terhadap penyakit kanker karat kayu (Uromycladium tepprianum) dapat diminimalisasi.

6. Tips Sukses Budidaya Sengon Solomon

Hasil Kultur in Vitro

Hal-hal yang perlu diperhatikan dalam budidaya sengon solomon hasil kultur in vitro adalah :
a. Pemilihan Bibit
Pilihlah bibit tanaman sengon solomon yang berkualitas.
b. Penyiapan lahan

Penyiapan lahan pada prinsipnya membebaskan lahan dari tumbuhan pengganggu dengan tujuan untuk memberikan ruang tumbuh kepada tanaman yang akan dibudidayakan. Cara pelaksanaan persiapan lahan dimulai dari pembukaan lahan, pembersihan lahan dengan membuat lubang untuk tanaman sengon.

c. Tahap penanaman Masukkan pupuk kompos+NPK 2,5 gr (campur) sebagai pupuk dasar diendapkan dilubang setinggi $30 \mathrm{~cm}$ (dapat langsung tanam atau 3-7 hr kemudian baru tanam). Kemudian masukkan bibit yang polibagnya sudah dibuka/disobek kedalam,dudukan yang benar/rata,lalu isi tanah kompos sebagai penutup akar dengan tanah setinggi 20 $\mathrm{cm}$ (jangan terlalu dipadatkan), hingga tersisa lubang $10 \mathrm{~cm}$ sebagai kantong air. Akan memaksimalkan pertumbuhan dan perkembangan sengon solomon.

d. Tahap Pemeliharaan

Di dalam pemeliharaan tanaman pohon sengon diperlukan beberapa hal untuk menunjang pertumbuhan pohon sengon solomon. Kegiatan pemeliharaan yang dilakukan berupa kegiatan penyulaman, penyiangan, pendangiran, pemangkasan, dan penjarangan. 


\section{KESIMPULAN}

Kesimpulan dari kegiatan pengabdian kepada masyarakat sebagai berikut. (1) Peningkatan kemampuan pembibit dalam membibit sengon telah berhasil dilakukan melalui penyuluhan dan pelatihan "Optimalisasi Pengelolaan Lahan Pekarangan/Kebun dengan Sengon Solomon Hasil Kultur in Vitro pada Kelompok Usaha Pembibitan Sengon Di Kabupaten Malang". (2) Peningkatan penyediaan benih-benih yang memiliki kualitas tinggi agar menghasilkan pohon dan hasil kayu yang bermutu telah berhasil dilakukan melalui budidaya sengon solomon hasil kultur in vitro. (3) Peningkatan bibit sengon unggul yang dihasilkan yang berdampak pada jumlah produksi bibit sengon telah berhasil dilakukan melalui budidaya sengon solomon hasil kultur in vitro.

\section{REFERENSI}

Anonimous. 1987. Hasil Perumusan Diskusi Sifat dan Kegunaan Jenis Kayu Hutan Tanaman Industri (HTI). Sylva Tropika. 2 (2). Warta Penelitian dan Pengembangan Kehutanan. Badan Litbang Kehutanan. Jakarta.

Laboratorium Silvikultur. 2007. Final Report Seed Source and Nursery Technology Development Project Genetic Material Selection and Collection of PotentialPlantation Tree Species. IPB. Bogor.

Lee, R. 2009. Berkebun Sengon. http://agromania@yahoogroups.com. Diakses tanggal 19 Oktober 2009.

NFTA World Education. 1991. Paraserianthes falcataria : Juara Pertumbuhan di Asia Tenggara. Lembar Informasi Pohon Pengikat Nitrogen. Konsorsium Pengembangan Dataran Tinggi Nusa Tenggara. Nitrogen Fixing Tree Associational. Studio Driya Media. Jakarta.

Martawijaya, A. dan I. Kartasujana. 1977. Ciri Umum, Sifat dan Kegunaan JenisJenis Kayu Indonesia. Publikasi Khusus. Lembaga Penelitian Hasil Hutan. Bogor.
RKPD Kabupaten Malang Tahun 2015. 2015.

Sanusi. 2008. Sengon. Trubus. http://www.trubus-online.co.id. Diakses tanggal 25 Agustus 2009. 